\title{
Treatment patterns and health care resource utilization associated with dalfampridine extended release in multiple sclerosis: a retrospective claims database analysis
}

\author{
This article was published in the following Dove Press journal: \\ ClinicoEconomics and Outcomes Research \\ 12 May 2016 \\ Number of times this article has been viewed
}

\section{Amy Guo' \\ Michael Grabner ${ }^{2}$ \\ Swetha Rao Palli² \\ Jessica Elder' \\ Matthew Sidovar' \\ Peter Aupperle' \\ Stephen Krieger ${ }^{3}$}

'Acorda Therapeutics Inc., Ardsley, New York, NY, USA; ${ }^{2}$ HealthCore Inc., Wilmington, DE, USA; ${ }^{3}$ Corinne Goldsmith Dickinson Center for MS, Icahn School of Medicine at Mount Sinai, New York, NY, USA
Correspondence: Amy Guo

Acorda Therapeutics Inc., 420 Saw Mill

River Road, Ardsley, New York,

NY 10502, USA

$\mathrm{Tel}+|9| 43265836$

Fax + I 9143265836

Email aguo@acorda.com
Background: Although previous studies have demonstrated the clinical benefits of dalfampridine extended release (D-ER) tablets in patients with multiple sclerosis (MS), there are limited realworld data on D-ER utilization and associated outcomes in patients with MS.

Purpose: The objective of this study was to evaluate treatment patterns, budget impact, and health care resource utilization (HRU) associated with D-ER use in a real-world setting.

Methods: A retrospective claims database analysis was conducted using the HealthCore Integrated Research Database ${ }^{\mathrm{SM}}$. Adherence (measured by medication possession ratio, or [MPR]) and persistence (measured by days between initial D-ER claim and discontinuation or end of follow-up) were evaluated over 1-year follow-up. Budget impact was calculated as cost per member per month (PMPM) over the available follow-up period. D-ER and control cohorts were propensity-score matched on baseline demographics, comorbidities, and MS-related resource utilization to compare walking-impairment-related HRU over follow-up.

Results: Of the 2,138 MS patients identified, 1,200 were not treated with D-ER (control) and 938 were treated with D-ER. Patients were aged 51 years on average and $74 \%$ female. Approximately $82.6 \%$ of D-ER patients were adherent (MPR $>80 \%$ ). The estimated budget impact range of D-ER was \$0.014-\$0.026 PMPM. Propensity-score-matched D-ER and controls yielded 479 patients in each cohort. Postmatching comparison showed that the D-ER cohort was associated with fewer physician $(21.5 \%$ vs $62.4 \%, P<0.0001)$ and other outpatient visits $(22.8 \%$ vs $51.4 \%$, $P<0.0001)$ over the 12-month follow-up. Changes in HRU from follow-up to baseline were lower in the D-ER cohort for metrics including walking-impairment-related hospitalizations and emergency department visits.

Conclusion: The majority of D-ER patients were adherent to treatment. D-ER utilization was associated with fewer walking-impairment-related physician and outpatient visits, with lower HRU increase over time. The budget impact of D-ER was low.

Keywords: budget impact, costs, real-world, health outcomes, walking impairment

\section{Introduction}

Multiple sclerosis (MS) is a complex, progressive, immune-mediated disease affecting more than 2.3 million people worldwide, including an estimated 400,000 in the United States. ${ }^{1}$ It is the third most common neurological cause of disability. ${ }^{2}$ Although symptoms vary widely and may fluctuate over time, the most common symptoms include fatigue, pain, weakness, spasticity, and gait disturbances. ${ }^{1}$ Most people with 
MS are diagnosed between 20 and 50 years of age and face considerable physical, emotional, and economic burdens. ${ }^{3}$ Direct medical costs were found to be nearly fivefold higher among those with newly diagnosed MS compared with healthy people. ${ }^{3}$ These costs become even higher when indirect costs, such as time lost from work, are considered. ${ }^{4}$

A significant portion of the burden of MS arises from the considerable disability caused by the disease over time, driven primarily by gait and motor disturbances. ${ }^{2,5}$ Approximately $75 \%$ of MS patients experience clinically significant walking disturbances. ${ }^{6}$ Regardless of the level of disability and disease duration, MS patients consider lower-limb function as their highest priority and a key component affecting their quality of life, ${ }^{7}$ independence, and perception of their ability to perform activities of daily living. ${ }^{8}$ MS patients with moderate and severe walking impairment face costs up to four and eight times higher, respectively, when compared with patients who are less disabled. ${ }^{9}$ Gait dysfunction is also associated with substantial social burden in terms of reduced productivity or inability to continue employment, disability, caregiver burden, and the need for physical and occupational therapy services, home modifications, and assistive devices. ${ }^{10}$

Based on consistent changes in walking speed demonstrated in clinical studies, ${ }^{11-14}$ dalfampridine extended-release (D-ER; known as prolonged-release fampridine in Europe and as fampridine modified- or sustained-release elsewhere) tablets, $10 \mathrm{mg}$ twice-daily, were approved by the US Food and Drug Administration in January 2010 to improve walking in MS patients. ${ }^{13}$

Although D-ER has been on the market for 5 years and has been prescribed to more than $200,000 \mathrm{MS}$ patients, ${ }^{15}$ there is limited information on its utilization and associated outcomes in a real-world environment. This study intends to fill the gap by investigating D-ER treatment patterns and budget impact as well as associated walking-impairment-related health care resource utilization (HRU).

\section{Methods}

\section{Data source}

This retrospective observational study used data from the HealthCore Integrated Research Database (HIRD ${ }^{\mathrm{SM}}$, Wilmington, DE, USA). The HIRD consists of longitudinal pharmacy and medical-claims data associated with a large US commercial health insurer including, but not limited to, patient demographics, clinical characteristics, and treatment information such as medication use, laboratory tests, physician office visits, and hospital and emergency department (ED) visits.
This study was exempt from Institutional Review Board review and was fully compliant with applicable provisions of the Health Insurance Portability and Accountability Act. Patient confidentiality was maintained throughout the study, and all data remained anonymous as researchers had access to relevant datasets only after all individual patient identifiers were removed.

\section{Study cohorts}

For this study, claims connected to 20.3 million lives from a geographically diverse US population between January 1, 2009, and February 29, 2013, were extracted from the HIRD. The earliest D-ER claim was set as index date, and the index period was defined as January 1, 2010, to February 29, 2012. Patients were required to have at least two preindex MSrelated claims (International Classification of Diseases, Ninth Revision, Clinical Modification [ICD-9-CM] diagnosis code 340.xx) or pharmacy claims for disease-modifying therapies (DMTs) and have at least 12 months of preindex and postindex continuous enrollment. Patients were excluded from the analysis if they were $<18$ years old or had other etiologies of gait/movement dysfunction as indicated by medical claims for stroke, Parkinson's disease, neoplasm of the brain, brain abscess, tendonitis or tendon injury, and/or cerebral palsy during the 12-month preindex period.

Patient baseline demographic and clinical characteristics were evaluated during the 12-month baseline period. Comorbidity burden was assessed via the Quan-Charlson comorbidity index (QCI). ${ }^{16}$ Individual comorbid conditions and symptoms commonly associated with MS were assessed based on ICD-9-CM codes. DMTs and other pharmacotherapeutic agents were identified based on generic product identifier and current procedure terminology codes.

A control cohort of patients was constructed for comparison of HRU and cost differences to the D-ER cohort. The control cohort contained patients with similar inclusion criteria to the D-ER cohort, except for requiring $\geq 1$ claim for a walking-related disorder (ICD-9-CM 781.0x, 781.2x, $781.3 x$, or $719.7 x$; earliest claim was set as index date) and with no D-ER use.

\section{Data analyses}

\section{D-ER treatment patterns and budget impact}

\section{Treatment patterns}

D-ER treatment patterns were evaluated during the 12-month postindex period (inclusive of index date) and included 
D-ER prescription-fill dose, number of D-ER prescription fills, D-ER daily pill count, and the time between prescription fills for patients with at least two D-ER prescriptions. Discontinuation was defined as a prescription-fill gap of $>30$ days past the expected refill date, which was defined as the last refill date plus days' supply as noted on the D-ER refill claim. ${ }^{17}$ Patients were considered persistent until discontinuation occurred. Persistence was measured as the time (days) between the index date and the date of discontinuation. For patients who did not discontinue, the number of days from index date to the end of the 12-month follow-up period was considered as the duration of persistence. A medication restart was defined as a refill of D-ER following discontinuation. Adherence to D-ER treatment was defined as the proportion of patients with a medication possession ratio (MPR) of $\geq 80 \% .{ }^{17} \mathrm{MPR}$ was calculated as the percentage of total number of days with D-ER pharmacy claims during the follow-up period divided by the number of days between the index date and the last refill date plus days' supply of the last refill.

\section{Budget impact}

Propensity-score matching was performed to balance the cohorts on baseline demographics and disease severity (see "Statistical Analysis" section). Estimates of cost offset by D-ER use were derived from the walkingimpairment-associated medical cost difference between the propensity-score-matched D-ER and control cohorts. Walking-impairment-associated medical costs included inpatient hospitalization, ED, physician office visits, and other outpatient visits (laboratory tests, outpatient procedures, and other miscellaneous items involving $\geq 1$ ICD-9-CM diagnosis for gait/movement dysfunction or walking-associated events). Budget impact was calculated as the cost of D-ER per member per month (PMPM) over the available follow-up period. Costs of D-ER were based on the cost of prescription fills for D-ER patients.

\section{Health care resource utilization}

HRU was compared between the propensity-score-matched D-ER and control cohorts. To control for potential confounding factors between cohorts due to the observational nature of the study, D-ER and control cohorts were propensity-score matched on baseline demographics, comorbidities, and MS-related resource utilization (see "Statistical Analysis" section).

Walking-impairment-related HRU was reported by place of service (inpatient hospitalization, ED, physician office visits, and other outpatient visits, which included laboratory tests, outpatient procedures, and other miscellaneous items) and was based on medical claims using the same ICD-9-CM codes as were used for control cohort identification (ICD-9-CM 781.0x, 781.2x, 781.3x, or $719.7 x$ ). Physical or occupational therapy visits were identified based on current procedure terminology codes. Differences over time in these HRU metrics (change scores, defined as follow-up minus baseline) were also calculated within each cohort.

\section{Statistical analysis}

Descriptive analysis included means (standard deviation [SD]) and frequencies for baseline continuous and categorical variables, respectively. Comparisons between D-ER and control cohorts used two-sample $t$-tests or Wilcoxon rank-sum tests for the normal or nonnormally distributed continuous variables, and $\chi^{2}$-tests or Fisher's exact tests for the categorical variables. Change scores were compared across cohorts using two-sample $t$-tests. A $P$-value $<0.05$ was prespecified to indicate statistical significance.

The propensity-score matching was developed using a logistic regression that determined the likelihood (ie, propensity) of each patient initiating D-ER compared with those not initiating D-ER. ${ }^{18-20}$ A 1:1 D-ER-to-control match was conducted using each patient's propensity score. Balance across cohorts after matching was assessed using statistical testing as well as standardized differences. Standardized differences of $>10$ were considered to have potential clinical significance. $^{21}$

\section{Sensitivity analysis}

To adjust for the difference in walking-impairmentrelated events at baseline between the D-ER and control cohorts, a subgroup analysis was conducted including only those patients with no medical claims for walking-related disorders prior to the index date in both the D-ER and control cohorts. HRU was compared across the two subgroups. This allowed balancing of D-ER and control cohorts with regard to walkingimpairment-related claims prior to index date (in the main analysis patients with medical claims for walkingrelated disorders prior to the index date were excluded only in the control cohort). The aim of this sensitivity analysis was to assess if the difference in walking-impairment-related claims prior to index date in the D-ER and control cohorts had biased the HRU comparison between the two. 


\section{Results}

\section{Patient demographics and clinical characteristics at baseline}

A total of 2,138 patients (938 D-ER; 1,200 control) met all study inclusion criteria (Figure 1). Patients were aged 51 years on average, with more than $73 \%$ female (Table 1). A large proportion of patients were treated by a neurologist (42.2\%). The comorbidity burden, as measured by the QuanCharlson comorbidity index, was low, suggesting a low overall prevalence of mortality-predictive complications (mean 0.74; Table 1). Muscular weakness or spasticity was the most frequently reported MS symptom (18.1\%), followed by disturbances of skin sensation (16.1\%) and dizziness (giddiness or vertiginous symptoms; 9.7\%). The most commonly prescribed DMT at baseline was interferon$\beta$-1a (23.3\%), followed by glatiramer acetate $(21.5 \%)$. Pain medications were the most frequently prescribed medication class at baseline (48.3\%), followed by antidepressants $(46.5 \%)$.

\section{D-ER treatment patterns and budget impact}

Median dose on the index date prescription fill was $20 \mathrm{mg}$, and average daily pill count was 1.98 (SD, 0.2), suggesting that it is likely that D-ER was prescribed in a manner consistent with its recommended daily dose of $20 \mathrm{mg}$ taken as two $10 \mathrm{mg}$ tablets. During the 12-month follow-up period, $78.3 \%(n=734)$ filled their D-ER prescription two or more

HealthCore Integrated Research Database

January 1, 2010 through February 29, 2012

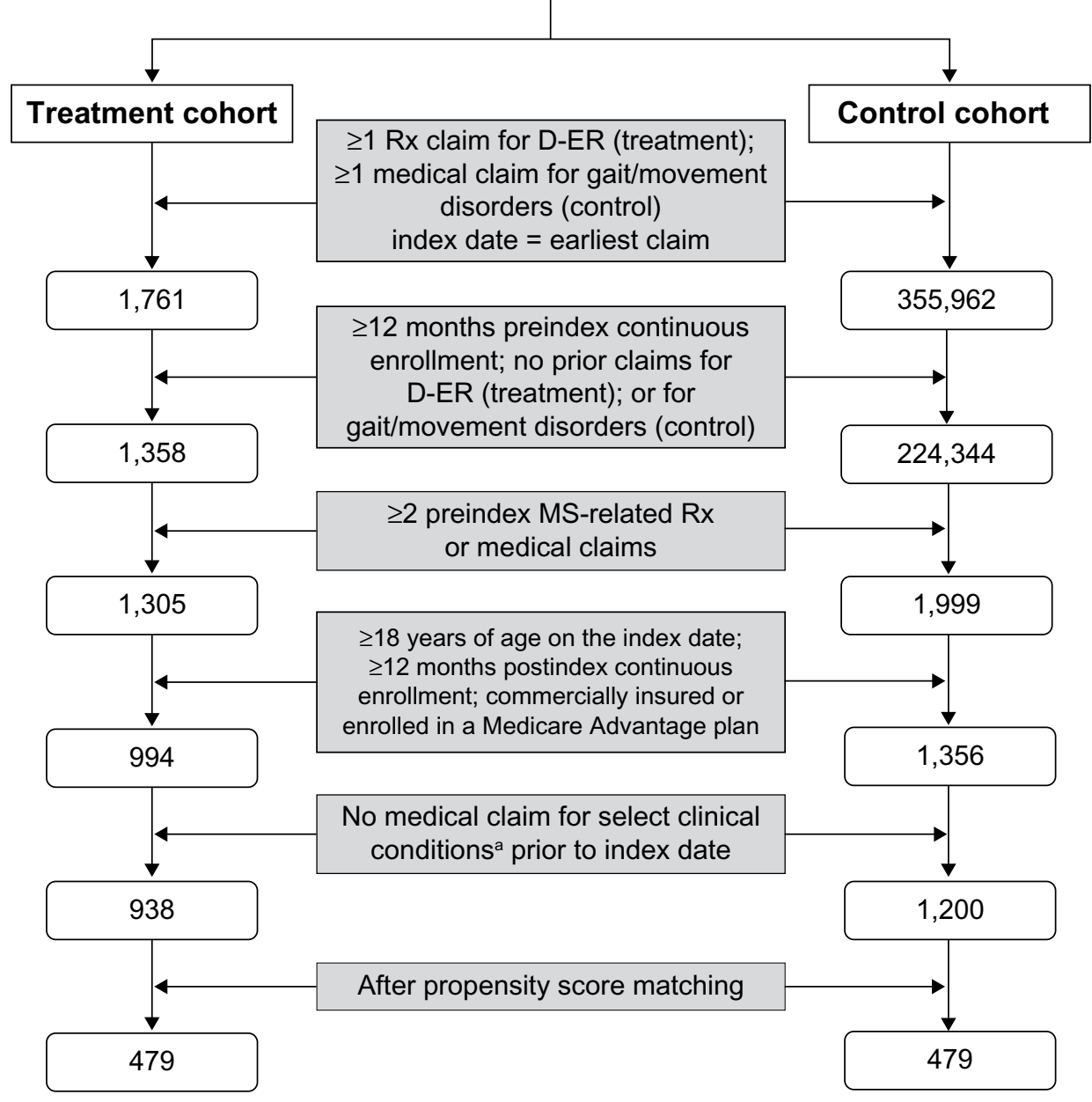

Figure I Attrition flow diagram.

Notes: ${ }^{a}$ No medical claims for stroke, Parkinson's disease, neoplasm of brain, brain abscess, tendonitis/tendon injury, and/or cerebral palsy during the 12 -month baseline period.

Abbreviations: D-ER, dalfampridine extended release; MS, multiple sclerosis; Rx, prescription. 
Table I Baseline demographics and clinical characteristics

\begin{tabular}{|c|c|}
\hline & $\begin{array}{l}\text { All patients } \\
(n=2,138), n(\%)\end{array}$ \\
\hline Receiving D-ER & $938(43.9)$ \\
\hline Female & $1,575(73.7)$ \\
\hline Age, mean (SD) & $51.2(11.1)$ \\
\hline \multicolumn{2}{|l|}{ Geographic region } \\
\hline Northeast & $485(22.7)$ \\
\hline South & $516(24.1)$ \\
\hline Midwest & $633(29.6)$ \\
\hline West & $439(20.5)$ \\
\hline Medicare Advantage & $292(13.7)$ \\
\hline \multicolumn{2}{|l|}{ Treating/prescribing physician specialty } \\
\hline Neurologist & $903(42.2)$ \\
\hline PCP & $295(13.8)$ \\
\hline Rehabilitation & $39(1.8)$ \\
\hline Others & $482(22.5)$ \\
\hline Missing/unknown & $419(19.6)$ \\
\hline Quan-Charlson comorbidity index score, mean (SD) & $0.74(1.26)$ \\
\hline \multicolumn{2}{|l|}{ MS symptoms ${ }^{\mathrm{a}}$} \\
\hline Muscular weakness/spasticity & $387(18.1)$ \\
\hline Disturbances of skin sensation & $345(16.1)$ \\
\hline Dizziness/giddiness/vertiginous syndromes & $207(9.7)$ \\
\hline Visual disturbances (including optic neuritis) & $|5|(7.1)$ \\
\hline \multicolumn{2}{|l|}{ Comorbidities $^{a}$} \\
\hline Hypertension & $911(42.6)$ \\
\hline Urinary tract infections & $456(21.3)$ \\
\hline Depression & $506(23.7)$ \\
\hline Thyroid disease & $296(13.8)$ \\
\hline Arthritis (rheumatoid and osteoarthritis) & $277(12.9)$ \\
\hline Hypercholesterolemia & $272(12.7)$ \\
\hline Diabetes mellitus (type I or II) & $202(9.5)$ \\
\hline Anxiety & $157(7.3)$ \\
\hline Nonskin cancer & $134(6.3)$ \\
\hline \multicolumn{2}{|l|}{ Baseline pharmacotherapies ${ }^{a}$} \\
\hline Pain medications & $\mathrm{I}, 033(48.3)$ \\
\hline Antidepressants & $994(46.5)$ \\
\hline Corticosteroids & $884(4 I .4)$ \\
\hline Anticonvulsants & $713(33.4)$ \\
\hline Adrenals & $572(26.8)$ \\
\hline Urinary antibiotics & $210(9.8)$ \\
\hline \multicolumn{2}{|l|}{ Preindex MS-associated DMTs ${ }^{a}$} \\
\hline Glatiramer acetate & $460(21.5)$ \\
\hline Interferon- $\beta-$ Ia & $498(23.3)$ \\
\hline Interferon- $\beta-I b$ & $165(7.7)$ \\
\hline Natalizumab & $234(10.9)$ \\
\hline
\end{tabular}

Notes: anly those with prevalence $\geq 5 \%$ are listed. All values are $\mathrm{n}(\%)$ unless stated otherwise.

Abbreviations: D-ER, dalfampridine extended release; DMT, disease-modifying therapy; MS, multiple sclerosis; PCP, primary care physician, including family/general and internal medicine; SD, standard deviation.

times (including the index date prescription fill), with a mean of 4.9 (SD, 4.3) prescription fills (Table 2). The mean MPR was $0.8(\mathrm{SD}, 0.3)$, with $82.6 \%(\mathrm{n}=775)$ having an MPR of $80 \%$ or higher.

The gross budget impact of D-ER was calculated as total cost of D-ER (mean monthly cost per patient multiplied by number of D-ER patients) divided by total number of health
Table 2 D-ER treatment patterns

\begin{tabular}{|c|c|}
\hline & $\begin{array}{l}\text { D-ER } \\
\text { Patients } \\
(n=938)\end{array}$ \\
\hline \multicolumn{2}{|l|}{ Index fill dose (mg) } \\
\hline Mean (SD) & $19.6(2.3)$ \\
\hline Median (QI-Q3) & $20(20-20)$ \\
\hline \multicolumn{2}{|l|}{ Daily pill count } \\
\hline Mean (SD) & $2.0(0.2)$ \\
\hline Median (QI-Q3) & $2(2-2)$ \\
\hline Number of patients with $\geq 2$ fills, $n$ (\%) & $734(78.3)$ \\
\hline \multicolumn{2}{|l|}{ Number of prescription refills } \\
\hline Mean (SD) & $4.9(4.3)$ \\
\hline Median (QI-Q3) & $4(1-9)$ \\
\hline \multicolumn{2}{|l|}{ Time between each fill in days, (SD) } \\
\hline Mean (SD) & $0.8(0.4)$ \\
\hline Patients who discontinued (allowed gap of 30 days), $\mathrm{n}$ (\%) & $697(74.3)$ \\
\hline Persistence in days, mean (SD) & $181.1(137.4)$ \\
\hline Patients who restarted (allowed gap of 30 days) & $185(26.5)$ \\
\hline \multicolumn{2}{|l|}{ MPR } \\
\hline Mean (SD) & $0.8(0.3)$ \\
\hline$M P R \geq 80 \%, n(\%)$ & $775(82.6)$ \\
\hline
\end{tabular}

plan members (\$0.026 PMPM). Similarly, the budget impact of non-D-ER walking-related medical treatments was calculated as the total cost of medical treatments for non-D-ER patients divided by total number of health plan members. Non-D-ER walking-related budget impact was \$0.013 PMPM vs $\$ 0.018$ PMPM for the propensity-score-matched D-ER vs control cohort and was $\$ 0.013$ PMPM vs $\$ 0.025$ PMPM for the unmatched cohorts. The budget impact difference between D-ER and control cohorts was potentially due to cost offset when treated by D-ER. The differences were estimated to be $\$ 0.005$ and $\$ 0.012$ PMPM for propensity-scorematched and unmatched cohorts. Therefore, the estimated net budget impact of D-ER was $\$ 0.021$ and $\$ 0.014$ PMPM for the propensity-score-matched and unmatched cohorts, respectively. The range of D-ER budget impact was thus estimated to be between $\$ 0.014$ and \$0.026 PMPM.

\section{Health care utilization}

A total of 958 patients remained after the matching, with 479 patients in each cohort. The baseline demographic and clinical characteristics post-matching are reported in Table S1. Compared with the D-ER cohort, the control cohort had significantly more physician office visits $(62.4 \% \mathrm{vs}$ $21.5 \%, P<0.0001)$, particularly neurologist visits $(45.5 \%$ vs $13.8 \% P<0.0001)$. Table 3 shows a comparison of mean number of visits per patient. Other outpatient office visits were also higher in the control cohort than in the 
Table 3 Walking impairment-related health care resource utilization over 12-month follow-up for treatment vs control cohorts post-matching

\begin{tabular}{|c|c|c|c|}
\hline & $\begin{array}{l}\text { Treatment cohort } \\
(\mathrm{n}=479)\end{array}$ & $\begin{array}{l}\text { Control cohort } \\
(n=479)\end{array}$ & $P$-value \\
\hline \multicolumn{4}{|l|}{ Inpatient hospitalizations } \\
\hline Number of hospitalizations per patient, mean (SD) & $0.04(0.2)$ & $0.1(0.3)$ & 0.2297 \\
\hline Total number of hospitalizations, $\mathrm{n}$ & 21 & 31 & \\
\hline \multicolumn{4}{|l|}{ ED visits } \\
\hline Number of ED visits per patient, mean (SD) & $0(0.1)$ & $0.0(0.1)$ & 0.2049 \\
\hline Total number of ED visits, $n$ & 2 & 6 & \\
\hline \multicolumn{4}{|l|}{ Physician office visits } \\
\hline Number of physician office visits per patient, mean (SD) & $0.4(1.0)$ & $1.0(1.3)$ & $<0.0001$ \\
\hline Total number of physician office visits, $n$ & 206 & 496 & \\
\hline \multicolumn{4}{|l|}{ Neurologist visits } \\
\hline Number of neurologist visits per patient, mean (SD) & $0.3(0.7)$ & $0.7(1.1)$ & $<0.0001$ \\
\hline Total number of neurologist visits, $\mathrm{n}$ & 118 & 354 & \\
\hline \multicolumn{4}{|l|}{ Other outpatient visits } \\
\hline Number of outpatient visits per patient, mean (SD) & $1.9(5.3)$ & $3.5(7.5)$ & 0.0001 \\
\hline Total number of outpatient visits, $n$ & 894 & 1,673 & \\
\hline \multicolumn{4}{|l|}{ PT/OT visits } \\
\hline Number of PT/OT visits per patient, mean (SD) & I.5 (4.5) & $3.0(7.3)$ & 0.0001 \\
\hline Total number of PT/OT visits, $n$ & 728 & 1,455 & \\
\hline
\end{tabular}

Notes: $P$-values are from two-sample $t$-tests or Wilcoxon rank-sum tests. A $P$-value $<0.05$ was prespecified to indicate statistical significance.

Abbreviations: ED, emergency department; PT/OT, physical therapy and/or occupational therapy; SD, standard deviation.

treatment cohort $(51.4 \%$ vs $22.8 \%, P<0.0001)$. Changes in walking-impairment-related HRU from follow-up to baseline (Table 4) showed that HRU metrics, including inpatient hospitalizations, ED visits, physician office visits, and other outpatient visits increased significantly more in the control cohort compared with the D-ER cohort.

To adjust for the differences in walking-impairmentrelated events at baseline between D-ER and control cohorts, a sensitivity analysis was performed on a subgroup of patients

Table 4 Change in scores in walking impairment-related health care resource utilization from baseline to follow-up period for treatment vs control cohorts post-matching

\begin{tabular}{|c|c|c|c|}
\hline Change scores & $\begin{array}{l}\text { D-ER cohort } \\
(n=479)\end{array}$ & $\begin{array}{l}\text { Control cohort } \\
(n=479)\end{array}$ & $P$-value \\
\hline \multicolumn{4}{|l|}{ Inpatient hospitalizations } \\
\hline Mean number of hospitalizations per patient & 0.02 & 0.06 & 0.0089 \\
\hline Total number of hospitalizations & 8 & 31 & \\
\hline \multicolumn{4}{|l|}{ ED visits } \\
\hline Mean number of ED visits per patient & -0.01 & 0.01 & 0.029 \\
\hline Total number of ED visits & -3 & 6 & \\
\hline \multicolumn{4}{|l|}{ Physician office visits } \\
\hline Mean number of physician office visits per patient & -0.13 & 1.04 & $<0.000$ I \\
\hline Total number of physician office visits & -63 & 496 & \\
\hline \multicolumn{4}{|l|}{ Neurologist visits } \\
\hline Mean number of neurologist visits per patient & -0.11 & 0.74 & $<0.0001$ \\
\hline Total number of neurologist visits & -52 & 354 & \\
\hline \multicolumn{4}{|l|}{ Other outpatient visits } \\
\hline Mean number of outpatient visits per patient & 0.30 & 3.49 & $<0.0001$ \\
\hline Total number of outpatient visits & 144 & 1,673 & \\
\hline \multicolumn{4}{|l|}{ Physical and/or occupational therapy } \\
\hline Mean number of PT/OT visits per patient & 0.19 & 3.04 & $<0.0001$ \\
\hline Total number of PT/OT visits & 92 & $\mathrm{I}, 455$ & \\
\hline
\end{tabular}

Notes: Numbers represent change scores, calculated as value at follow-up minus value at baseline for each metric. Change score units reflect units of the underlying metric. For example, the change score of 0.02 for inpatient hospitalizations in the D-ER cohort reflects an increase from a mean number of hospitalizations per person of 0.03 at baseline to 0.04 at follow-up (rounded). P-values are from two-sample $t$-tests. A $P$-value $<0.05$ was prespecified to indicate statistical significance.

Abbreviations: D-ER, dalfampridine extended release; ED, emergency department; PT/OT, physical therapy and/or occupational therapy. 
from both cohorts with no medical claims for walkingrelated disorders prior to the index date. Comparison of HRU between the two subgroups showed that the findings were broadly consistent with that from the main analysis (Table S2).

\section{Discussion}

This analysis is one of the first to evaluate D-ER treatment patterns, budget impact, and HRU of MS patients in a large, real-world US population. The D-ER treatment patterns observed in our analysis appeared to be consistent with the recommendations from the D-ER prescribing information with respect to dosage and frequency of medication intake. The majority of patients who initiated D-ER were adherent to therapy.

We used propensity-score matching to select a control cohort of non-D-ER users. The use of propensity-score matching reduced selection bias by including subjects who are comparable on a broad range of baseline demographic, clinical, and economic characteristics. A comparison of propensity-score-matched D-ER and control cohorts showed that walking-impairment-related physician visits and other outpatient visits were significantly higher in the control cohort during the follow-up period. Additionally, metrics of walking-impairment-related HRU increased at a higher rate from baseline to follow-up in the control cohort, suggesting a faster increase in HRU over time in the control cohort. One possible explanation is that improvement in walking in the D-ER cohort may have resulted in less HRU. In this regard, a recent claims study that examined the treatment patterns and medical costs of MS patients treated with prolonged-release fampridine in Germany showed that treatment was associated with significant reductions in the number of MS-related inpatient hospitalizations, length of stay, and costs when compared before and after treatment. ${ }^{22}$

The budget impact of D-ER in this study population was estimated at \$0.014-\$0.026 PMPM, with and without taking into consideration the potential cost offset due to D-ER treatment. This budget impact of D-ER is minimal in comparison to that of MS specialty drugs, as reported in a study that benchmarked specialty drug costs by therapeutic class. The budget impact for MS specialty drugs in 2010 was $\$ 2.54$ PMPM. $^{23}$

Our analysis suggests that a significantly greater number of patients receiving D-ER were taking DMTs at baseline compared with the control cohort, which may reflect higher levels of disease severity, or more thorough care management. A relatively high proportion of patients did not persist on
D-ER treatment throughout the 12-month follow-up period. Further studies assessing association of persistence and outcomes are warranted.

\section{Limitations}

Although this study was based on a large and geographically diverse patient population, several limitations exist. As with any claims database analysis, the presence of a diagnosis code on a medical claim is not a confirmation of the presence of a disease, as the diagnosis code may have been incorrectly entered or included as a rule-out criterion. Specifically, walking-related disorders may have been undercoded or miscoded within claims, potentially resulting in the underestimation of walking-impairment-related health care burden. Similarly, the absence of a code does not necessarily indicate that the disease or condition was not present. In addition, a claim for a filled prescription does not indicate that the medication was consumed or that it was taken as prescribed. Furthermore, the effect of some patient demographics as well as clinical and disease-specific parameters, such as race, education, body mass index, disease severity, or types of MS, could not be assessed in the claims data and could have affected outcomes.

Propensity-score matching was used to generate cohorts balanced on observable characteristics to reduce the bias However, it is possible that some bias remains due to unobservable characteristics. Finally, the study sample was taken from one large US commercial health plan, and the results may not be generalizable to patients enrolled in different plans, uninsured patients, or people with MS living outside of the United States.

\section{Conclusion}

This analysis is one of the first to evaluate treatment patterns, resource utilization, and the budget impact of D-ER in a large, real-world population of MS patients. Treatment patterns of patients initiating D-ER seemed to be consistent with prescribing recommendations. The use of D-ER was associated with a lower number of walking-impairment-related physician and other outpatient office visits among patients with MS over 12-month follow-up, while inpatient hospitalization and ED utilization were directionally lower in the treatment group. Changes from follow-up to baseline in HRU metrics (inpatient hospitalization, ED, physician office visits, and other outpatient visits) were found to be lower in the treatment cohort, indicating a trend of lower HRU over time in the treatment cohort. Results of this real-world analysis suggest D-ER may lead to cost offsets through reductions in 
HRU. Future research should examine the robustness of our results in different and larger real-world populations as well as the effect of D-ER adherence on clinical and economic outcomes.

\section{Acknowledgments}

The authors acknowledge Cheryl Jones, an employee of HealthCore, Inc., for editorial assistance in preparing the manuscript that was funded by Acorda Therapeutics, Inc. The authors are also grateful to Alexander Niyazov for his critical review of the manuscript and editorial contribution. Funding for this study and for editorial support was provided by Acorda Therapeutics, Inc.

\section{Disclosure}

Amy Guo, Matthew Sidovar, and Peter Aupperle are employees and stockholders of Acorda Therapeutics Inc. Stephen Krieger is a consultant for Acorda Therapeutics Inc., Biogen Idec, Genentech Inc., Genzyme Corporation, Questcor Pharmaceuticals Inc., Teva Pharmaceutical Industries Ltd., and is a member of the Scientific Advisory Board for Acorda Therapeutics Inc., Bayer, Biogen Idec, Questcor Pharmaceuticals Inc. and Teva Pharmaceutical Industries Ltd. Michael Grabner is an employee of HealthCore, Inc., an independent research organization that received funding from Acorda Therapeutics Inc. for the conduct of the study. Swetha Palli was an employee of HealthCore Inc. at the time the study was conducted. Jessica Elder was a contractor to Acorda Therapeutics Inc. at the time the study was conducted. The authors report no other conflicts of interest in this work.

\section{References}

1. National Multiple Sclerosis Society. MS prevalence. Available from: http://www.nationalmssociety.org/About-the-Society/MS-Prevalence. Accessed April 28, 2015.

2. Bethoux F, Bennett S. Evaluating walking in patients with multiple sclerosis: which assessment tools are useful in clinical practice? Int $J$ MS Care. 2011;13(1):4-14.

3. Asche CV, Singer ME, Jhaveri M, et al. All-cause health care utilization and costs associated with newly diagnosed multiple sclerosis in the United States. J Manag Care Pharm. 2010;16(9):703-712.

4. Adelman G, Rane SG, Villa KF. The cost of multiple sclerosis in the United States. A systematic review of the literature. J Med Econ. 2013;16(5):639-647.

5. Zwibel HL. Contribution of impaired mobility and general symptoms to the burden of multiple sclerosis. Adv Ther. 2009;26(12):1043-1057.
6. Hobart J, Lamping D, Fitzpatrick R, et al. The multiple sclerosis impact scale (MSIS-29): a new patient-based outcome measure. Brain. 2001;124(Pt 5):962-973.

7. Heesen C, Böhm J, Reich C, et al. Patient perception of bodily functions in multiple sclerosis: gait and visual function are the most valuable. Mult Scler. 2008;14(7);988-991.

8. Paltamaa J, Sarasoja T, Leskinen E, et al. Measures of physical functioning predict self-reported performance in self-care, mobility, and domestic life in ambulatory persons with multiple sclerosis. Arch Phys Med Rehabil. 2007;88(12):1649-1657.

9. Patwardhan MB, Matcher DB, Samsa GP, et al. Cost of multiple sclerosis by level of disability: a review of literature. Mult Scler. 2005;11(2):232-239.

10. Miravalle AA. Guidelines and best practices for appropriate use of dalfampridine in managed care populations. Am J Manag Care. 2011;17(Suppl 5):S154-S160.

11. Goodman AD, Brown TR, Krupp L, et al. Sustained release of oral fampridine in multiple sclerosis: a randomised, double-blind, controlled trial. Lancet. 2009;373(9665):732-738.

12. Goodman AD, Brown TR, Edwards KR, et al. A phase 3 trial of extended release oral dalfampridine in multiple sclerosis. Ann Neurol. 2010;68(4):494-502.

13. Ampyra ${ }^{\circledR}$ (dalfampridine) extended release (ER) tablets [prescribing information]. Ardsley, NY: Acorda Therapeutics, Inc; 2014.

14. Goodman AD, Brown TR, Schapiro RT, et al. A pooled analysis of two phase 3 clinical trials of dalfampridine in patients with multiple sclerosis. Int J MS Care. 2014;16(3):153-160.

15. Jara M, Aquilina T, Aupperle P, et al. Safety profile of dalfampridine extended release in multiple sclerosis: 5-year post-marketing experience in the United States. Poster presented at: ECTRIMS, October 9, 2015; Barcelona, Spain.

16. Quan H, Sundararajan V, Halfon P, et al. Coding algorithms for defining comorbidities in ICD-9-CM and ICD-10 administrative data. Med Care. 2005;43(11):1130-1139.

17. Peterson AM, Nau DP, Cramer JA, et al. A checklist for medication compliance and persistence studies using retrospective databases. Value Health. 2015;10(1):3-12.

18. Rosenbaum PR, Rubin DB. The central role of the propensity score in observational studies for causal effects. Biometrika. 1983;70(1): 41-55.

19. D'Agostino RB. Tutorial on biostatistics: propensity score methods for bias reduction in the comparison of a treatment to a non-randomized control group. Stat Med. 1998;17(19):2265-2281.

20. Kurth T, Walker AM, Glynn RJ, et al. Results of multivariable logistic regression, propensity matching, propensity adjustment, and propensitybased weighting under conditions of nonuniform effect. Am J Epidemiol. 2006;163(3):262-270.

21. Austin PC. An introduction to propensity score methods for reducing the effects of confounding in observational studies. Multivariate Behav Res. 2011;46(3):399-424.

22. Lee A, Liu Y, Gleissner E, et al. Treatment patterns and costs among patients with multiple sclerosis treated with prolonged-release fampridine in Germany. Poster presented at: ECTRIMS; October 9, 2015, Barcelona, Spain.

23. Milliman Research Report. Milliman Specialty Medical Drug 2010 Commercial Benchmark Study; November 26, 2012. Brookfield, WI: Milliman Research Report. Available from: http:/us.milliman.com/ uploadedFiles/insight/Research/health-rr/pdfs/specialty-medical-drugbenchmark-study.pdf. Accessed November 2, 2015. 


\section{Supplementary materials}

Table SI Baseline demographics and clinical characteristics in the matched cohorts

\begin{tabular}{|c|c|c|c|c|}
\hline & $\begin{array}{l}\text { D-ER cohort } \\
(n=479)\end{array}$ & $\begin{array}{l}\text { Control cohort } \\
(n=479)\end{array}$ & $P$-value & $\begin{array}{l}\text { Standardized } \\
\text { difference }\end{array}$ \\
\hline \multicolumn{5}{|l|}{ Sex } \\
\hline Female & $356(74.32)$ & $352(73.49)$ & 0.7685 & 2 \\
\hline \multicolumn{5}{|l|}{ Age } \\
\hline Mean $( \pm$ SD) & $51.81( \pm 9.76)$ & $49.13( \pm 10.41)$ & $<0.0001$ & 27 \\
\hline Median & 53.00 & 52.00 & $<0.0001$ & \\
\hline \multicolumn{5}{|l|}{ Treating or prescribing physician specialty } \\
\hline Neurologist & $210(43.84)$ & $209(43.63)$ & 0.9481 & 0 \\
\hline All other specialties & $269(56.16)$ & $270(56.37)$ & & 0 \\
\hline PCP & $15 \mid(3 \mid .52)$ & $4 \mathrm{l}(8.56)$ & $<0.0001$ & 60 \\
\hline Rehabilitation & $2(0.42)$ & II (2.3) & & -16 \\
\hline Others & $31(6.47)$ & $|2|(25.26)$ & & -53 \\
\hline Missing/unknown & $85(17.75)$ & $97(20.25)$ & & -6 \\
\hline \multicolumn{5}{|l|}{ Quan-Charlson comorbidity index } \\
\hline Mean $( \pm S D)$ & $0.58( \pm 1.14)$ & $0.62( \pm \mathrm{I} . \mathrm{I})$ & 0.6454 & -3 \\
\hline \multicolumn{5}{|l|}{ MS symptoms } \\
\hline Muscular weakness/spasticity & $75(I 5.66)$ & $75(15.66)$ & 1.0000 & 0 \\
\hline Disturbances of skin sensation & $71(\mid 4.82)$ & $69(14.4 \mid)$ & 0.8549 & 1 \\
\hline Visual disturbances (including optic neuritis) & $38(7.93)$ & $34(7.1)$ & 0.6240 & 3 \\
\hline Dizziness/giddiness/vertiginous syndromes & $36(7.52)$ & $4 \mathrm{I}(8.56)$ & 0.5524 & -4 \\
\hline Migraine & $20(4.18)$ & $29(6.05)$ & 0.1869 & -9 \\
\hline \multicolumn{5}{|l|}{ Preindex MS-associated DMTs } \\
\hline Glatiramer acetate & $100(20.88)$ & $114(23.8)$ & 0.2775 & -7 \\
\hline Interferon- $\beta-$ Ia & $122(25.47)$ & I 33 (27.77) & 0.4213 & -5 \\
\hline Natalizumab & $6 \mathrm{I}(12.73)$ & $54(\mathrm{I} I .27)$ & 0.4865 & 4 \\
\hline Interferon- $\beta$-Ib & $43(8.98)$ & $4 \mid(8.56)$ & 0.8193 & 1 \\
\hline
\end{tabular}

Notes: $P$-values are from two-sample $t$-tests/Wilcoxon rank-sum tests (for continuous variables) and $X^{2}$-tests or Fisher exact tests (for categorical variables). A P-value $<0.05$ was prespecified to indicate statistical significance. All values are $\mathrm{n}(\%)$ unless stated otherwise.

Abbreviations: D-ER, dalfampridine extended release; DMTs, disease-modifying therapies; MS, multiple sclerosis; PCP, primary care physician, including family/general and internal medicine; SD, standard deviation.

Table S2 Sensitivity analysis: walking-impairment-related HRU over 12-month follow-up in a subgroup of matched patients without claims for walking-related disorders at baseline

\begin{tabular}{|c|c|c|c|}
\hline & $\begin{array}{l}\text { Treatment cohort } \\
(\mathrm{n}=300)\end{array}$ & $\begin{array}{l}\text { Control cohort } \\
(\mathrm{n}=300)\end{array}$ & $P$-value \\
\hline \multicolumn{4}{|l|}{ Inpatient hospitalizations } \\
\hline Number of hospitalizations per patient, mean (SD) & $0.0(0.2)$ & $0.1(0.3)$ & 0.0799 \\
\hline Total number of hospitalizations, $\mathrm{n}$ & 10 & 21 & \\
\hline \multicolumn{4}{|l|}{ ED visits } \\
\hline Number of ED visits per patient, mean (SD) & $0(0.1)$ & $0.01(0.1)$ & 0.3165 \\
\hline Total number of ED visits, $n$ & 1 & 3 & \\
\hline \multicolumn{4}{|l|}{ Physician office visits } \\
\hline Number of physician office visits per patient, mean (SD) & $0.1(0.4)$ & I.I (I.4) & $<0.0001$ \\
\hline Total number of physician office visits, $n$ & 28 & 326 & \\
\hline \multicolumn{4}{|l|}{ Neurologist visits } \\
\hline Number of neurologist visits per patient, mean (SD) & $0.1(0.3)$ & $0.7(1.2)$ & $<0.0001$ \\
\hline Total number of neurologist visits, $n$ & 14 & 220 & \\
\hline \multicolumn{4}{|l|}{ Other outpatient visits } \\
\hline Number of outpatient visits per patient, mean (SD) & $\mathrm{I} .3(4.7)$ & $3.5(7.8)$ & $<0.0001$ \\
\hline Total number of outpatient visits, $n$ & 396 & 1,043 & \\
\hline \multicolumn{4}{|l|}{ PT/OT visits } \\
\hline Number of PT/OT visits per patient, mean (SD) & I.I (3.7) & $3.1(7.6)$ & $<0.000$ I \\
\hline Total number of PT/OT visits, $n$ & 317 & 919 & \\
\hline
\end{tabular}

Notes: $P$-values are from two-sample $t$-tests or Wilcoxon rank-sum tests. A $P$-value $<0.05$ was prespecified to indicate statistical significance.

Abbreviations: ED, emergency department; HRU, health care resource utilization; PT/OT, physical therapy and/or occupational therapy; SD, standard deviation. 


\section{Publish your work in this journal}

ClinicoEconomics \& Outcomes Research is an international, peerreviewed open-access journal focusing on Health Technology Assessment, Pharmacoeconomics and Outcomes Research in the areas of diagnosis, medical devices, and clinical, surgical and pharmacological intervention. The economic impact of health policy and health systems

organization also constitute important areas of coverage. The manuscript management system is completely online and includes a very quick and fair peer-review system, which is all easy to use. Visit http://www.dovepress.com/testimonials.php to read real quotes from published authors.

Submit your manuscript here: http://www.dovepress.com/clinicoeconomics-and-outcomes-research-journal 